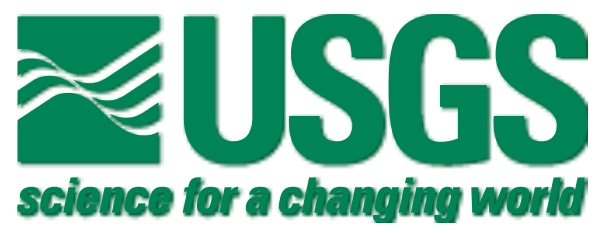

\title{
Geologic map and digital database of the Porcupine Wash 7.5 minute quadrangle, Riverside County, California
}

By Robert E. Powell

Digital preparation by Pamela M. Cossette ${ }^{1}$

Readme, version 1.0

Open-File Report 01-30

Online version 1.0

http://geopubs.wr.usgs.gov/open-file/01-30

2001

U.S. Department of the Interior

U.S. Geological Survey

Prepared in cooperation with

National Park Service

California Division of Mines and Geology

A product of the Southern California Areal Mapping Project

${ }^{1}$ U.S. Geological Survey, Western Region Earth Surface Processes Team W904 Riverside Avenue, Spokane, WA 99201-1087

For database limitations, see following page 


\section{DATABASE LIMITATIONS}

\section{Content}

This database is preliminary and has not been reviewed for conformity with U.S. Geological Survey editorial standards or with the North American Stratigraphic Code. Any use of trade, product, or firm names is for descriptive purposes only and does not imply endorsement by the U.S. Government.

This database, identified as " Geologic map and digital database of the Porcupine Wash 7.5 minute quadrangle, Riverside County, California," has been approved for release and publication by the Director of the U.S. Geological Survey. Although this database has been subjected to rigorous review and is substantially complete, the USGS reserves the right to revise the data pursuant to further analysis and review. Furthermore, it is released on the condition that neither the USGS nor the United States Government may be held responsible for any damages resulting from its authorized or unauthorized use.

\section{Spatial Resolution}

Use of this digital geologic map should not violate the spatial resolution of the data. The Porcupine Wash database was developed using digital orthophotograph quarter quadrangles (DOQQs) as a base. DOQQs have a pixel resolution of $1 \mathrm{~m}$ and are accurate to a scale of 1:12,000 ( $1 \mathrm{in}=1,000 \mathrm{ft})$. Any enlargement beyond 1:12,000 exceeds the spatial resolution of the geologic data and should not be used in lieu of a more detailed site-specific geologic evaluation. Similarly, the digital topographic base map is derived from the U.S. Geological Survey, 1:24,000-scale Porcupine Wash 7.5 minute quadrangle (provisional edition, 1986); any enlargement beyond 1:24,000 exceeds the spatial resolution of the topographic data. Where the geologic data is used in combination with the topographic data, the resolution of the combined output is limited by the lower resolution of the topographic data. Where this database is used in combination with other data of higher resolution, the resolution of the combined output will be limited by the lower resolution of these data. 


\section{Table of contents}

DATABASE LIMITATIONS

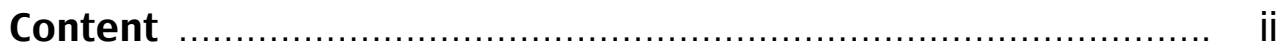

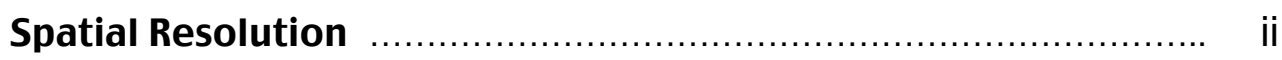

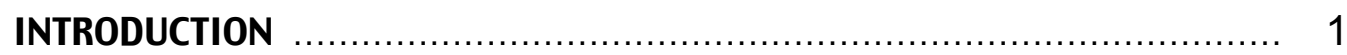

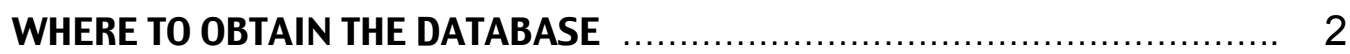

DATABASE INFORMATION AVAILABLE ON THE OPEN-FILE WEBSITE ....... 3

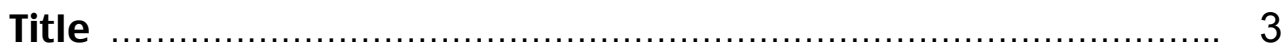

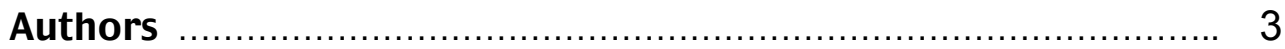

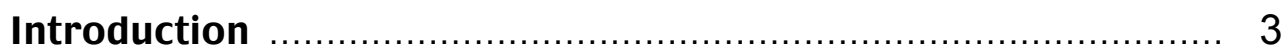

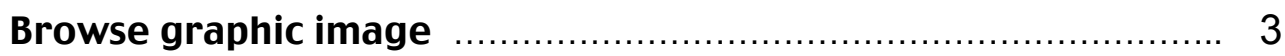

Explanatory files ............................................................ 3

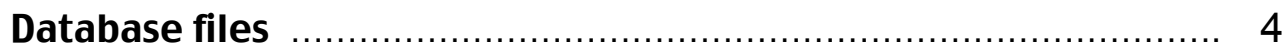

Files for viewing and plotting …….................................... 4

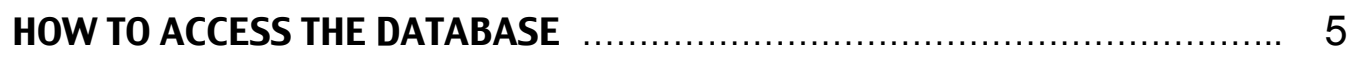

Extracting the database files ............................................ 5

Converting the ARC/INFO interchange/export files ................... 6

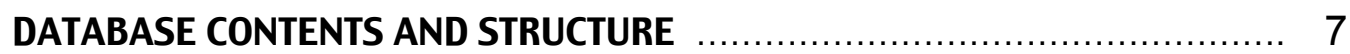

HOW TO OBTAIN A PAPER PLOT OF THE GEOLOGIC MAP _.................... 9

HOW TO ACCESS PORTABLE DOCUMENT FORMAT (.PDF) FILES ............. 10

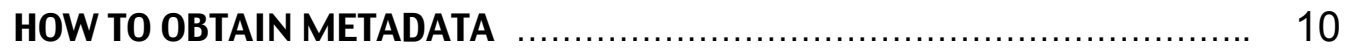

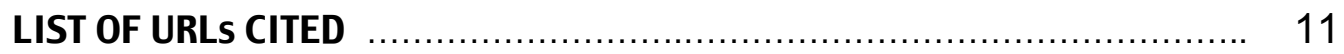

U.S. Geological Survey websites ......................................... 11

Software websites …….............................................. 12 


\section{INTRODUCTION}

Open-File Report 01-30 is a digital geologic data set that maps and describes the geology of the Porcupine Wash 7.5 minute quadrangle, Riverside County, southern California. The Porcupine Wash database is one of several quadrangle databases that are in preparation for Joshua Tree National Park and vicinity. These quadrangles are a subset of digital quadrangle maps being generated for the Southern California Areal Mapping Project (SCAMP). The SCAMP maps are, in turn, part of the nation-wide digital geologic map coverage being developed by the National Cooperative Geologic Map Project (NCGMP) of the U.S. Geological Survey (USGS).

The Porcupine Wash data set consists of a digital geologic map database accompanied by graphics, plot, and explanatory files. The digital database was created using ARCVIEW, version 3.2, and ARC/INFO, version 7.2.1, commercial Geographical Information System (GIS) software designed by Environmental Systems Research Institute (ESRI), Redlands, California (http://www.esri.com). The database includes five ARC/INFO map coverages: geology, dikes, structural data, ornamentation indicating relative movement of fault blocks, and leaders for annotated map unit symbols. It also contains a scanned 1:24,000-scale topographic base and supporting SCAMP symbolsets. PostScript and Portable Document Format files contain a geologic map generated from the database combined with map margin explanatory information created in Adobe Illustrator. Other PDF and ASCII text files contain metadata, a readme document, an explanatory pamphlet, and stand-alone versions of the map-margin Correlation of Map and Database Units (CMU) and Description of Map and Database Units (DMU). As yet, not all of the detailed information about geologic units contained in the map-margin explanation has been entered into the digital database.

The Porcupine Wash quadrangle lies between $115^{\circ} 45^{\prime}$ and $115^{\circ} 52^{\prime} 30^{\prime \prime}$ west longitude and $33^{\circ} 52^{\prime} 30^{\prime \prime}$ and $33^{\circ} 45^{\prime}$ north latitude. The 7.5 minute quadrangle is subdivided in latitude and longitude by a 2.5-minute tic grid that is marked on the topographic map. For the digital coverages, only the four corner tics that represent the geographic extent of the quadrangle have been generated mathematically in ARC/INFO. Geologic map information entered into ARC/INFO has been spatially registered using the four tics that represent the geographic extent of the quadrangle. Both the geologic database and the topographic base map are represented in polyconic projection referenced to the NAD27 datum. (See metadata for more information about projection.)

In mapping real-world geologic features into the database, geologic contacts, faults, and dikes are represented as lines (arcs), geologic units as polygons and regions, and sitespecific structural data as points. ARC/INFO records the spatial coordinates and topology of each feature and links it to a polygon, arc, or point attribute table (.pat, .aat, and .pat, respectively) that uniquely identifies the feature. Feature-attribute tables can be related to other tables that further describe and classify the geologic features. (See metadata and explanatory pamphlet for more information about geologic content of database.) 


\section{WHERE TO OBTAIN THE DATABASE}

The Porcupine Wash 7.5 minute quadrangle data set is available on the USGS Western Region Geologic Publications Server. The data set may be downloaded from the website

http://geopubs.wr.usgs.gov/open-file/01-30

or by anonymous ftp from the Publications Server:

Server: geopubs.wr.usgs.gov

Directory: /pub/open-file/of01-30.

The Porcupine Wash geologic map and database can also be accessed through links to the Western Region Geologic Publication Server by any of the following paths:

- http://geology.wr.usgs.gov/wgmt/scamp/scamp.html

This website provides links to SCAMP-related digital geologic mapping in southern California. The site lists new releases by year and title

- http://geopubs.wr.usgs.gov/

This website provides links to USGS Western Region digital geologic maps, including Open-File. The site lists new releases series and number

- http://geology.usgs.gov/open-file/maps.html

This website provides links to all digital USGS Open-File Reports that contain digital map databases. The site lists the Open-File Reports by number along with the title and author(s) of the report

- http://geo-nsdi.er.usgs.gov/cgi-bin/publication?open-file

This website provides links to all digital USGS Open-File Report maps via their metadata files. The site lists the Open-File Reports by number along with the title of the report (see 'How to obtain metadata' below) 


\section{DATABASE AS AVAILABLE ON USGS GEOPUBS SERVER}

On the USGS Western Region Geologic Publications Server (geopubs) website for the Porcupine Wash geologic map and digital database, information is arranged as follows:

\section{Title}

Geologic map and digital database of the Porcupine Wash 7.5 minute quadrangle, Riverside County, southern California

\section{Authors}

Robert E. Powell

Pamela M. Cossette (digital cartography)

\section{Introduction}

\section{Browse-graphic image}

Page-sized, non-navigable image of geologic map with marginal explanation

(pwash_browse.jpg: 35 KB JPEG image of geologic map with marginal explanation)

\section{Explanatory files}

- Readme tabulates contents of database and describes how to access them. Provided on website in ASCII text and Portable Document formats

- Metadata file contains detailed technical descriptions of structure and content of digital data. Provided on website as parseable text in ASCII format, and as outline in Hypertext Markup Language format. Also available on the USGS Geologic Division Node of the National Geospatial Data Clearinghouse in these two and other formats (see 'How to obtain metadata' below).

- Explanatory pamphlet describes approach used in building database, and discusses purpose, content, and geologic framework of database. Provided on website in ASCII text and Portable Document formats

File name

File type and description

File size

\begin{tabular}{|c|c|c|}
\hline pwash_readme.txt & ASCII readme file & $25 \mathrm{~KB}$ \\
\hline pwash_readme.pdf & PDF readme file & $116 \mathrm{~KB}$ \\
\hline pwash_pamph.txt & ASCII version of explanatory pamphlet & $50 \mathrm{~KB}$ \\
\hline pwash_pamph.pdf & PDF version of explanatory pamphlet & $163 \mathrm{~KB}$ \\
\hline pwash_met.txt & ASCII metadata file & $68 \mathrm{~KB}$ \\
\hline pwash_met.html & HTML metadata file & $88 \mathrm{~KB}$ \\
\hline
\end{tabular}




\section{Database files}

Database files are packaged as a tarred and gzipped file that bundles and compresses the following information:

- Database files: ASCII-formatted ARC/INFO interchange/export (.e00) file for each ARC/INFO coverage, symbolset, and dictionary. (See 'Database contents and structure' below.)

- ASCII text files for readme, metadata, and explanatory pamphlet

File name

File type and description

File size

pwash.tar.gz

GZIP compressed 25.5-MB TAR

$5.5 \mathrm{MB}$

bundle of all database files

\section{Files for viewing and plotting}

- Gzip-compressed PostScript plot-file for generating paper copy of geologic map with marginal explanation

- Portable Document Format file containing full-sized, navigable graphic image of geologic map with marginal explanation

- Portable Document Format files containing stand-alone versions of Description of Map and Database Units (DMU) and Correlation of Map and Database Units (CMU) from map-margin explanation

File name

File type and description

File size

pwash_map.ps.gz

Gzipped 244-MB PostScript plot file of map

$9.5 \mathrm{MB}$

with marginal explanation

pwash_map.pdf

PDF file containing geologic map

$5.4 \mathrm{MB}$

pwash_cmu.pdf

with marginal explanation

pwash_dmu.pdf

PDF Correlation of Map \& Database Units file

$54 \mathrm{~KB}$

PDF Description of Map \& Database Units file

$54 \mathrm{~KB}$ 


\section{HOW TO ACCESS THE DATABASE}

\section{Extracting the database files}

The Porcupine Wash database files have been bundled and compressed using tar and gzip utilities. Before attempting to unzip the file after downloading, be sure that the .gz extension is present in the file name.

Extraction creates the directory pwash/ that contains the database in ARC/INFO interchange (.e00) files, the topographic map in a GEOTIFF file, and the readme, metadata, and explanatory pamphlet in ASCII text files. The database interchange files include five ARC/INFO coverages and supporting symbolsets and dictionaries.

Tar and uncompress utilities are included in most UNIX systems, and are available free of charge for all systems at various websites:

Gnu Software: http://www.gnu.org/order/ftp.html (UNIX tar and gzip)

(This web page links to mirror archive sites for Gnu tar and gzip utilities)

Gnu zip: http://www.gzip.org (UNIX gzip)

CNET Shareware: http://shareware.cnet.com/ (Macintosh and Windows)

(Search for 'tar' or 'gzip' for any Macintosh or Windows operating system.)

WinZip: http://www.winzip.com (Windows gzip)

USGS Public Domain Software web page: http://edcwww.cr.usgs.gov/doc/edchome/ndcdb/public.html (UNIX and Macintosh) (Provides links to Washington University at St. Louis Gnu archive for UNIX tar and gzip; and to AOL mirror site for Macintosh tar and gzip)

Internet Literacy's Common Internet File Formats: http://www.matisse.net/files/formats.html (Macintosh and Windows tar and gzip) (Note: this website has not been maintained since December 1995) 


\section{Converting the ARC/INFO interchange/export files}

The ARC interchange/export (.e00) files are converted to ARC coverages using the ARC command IMPORT.

1. Change directories to the pwash/ directory

2. At the UNIX command prompt, launch ARC/INFO by typing "arc"

3. From the ARC command line type:

import $<$ option $><$ interchange_file $><$ output $>$

(e.g., import auto pwash_geo pwash_geo; repeat for each interchange file)

Consult the ARC/INFO command references manual in ESRI's software documentation for other $<$ option $>$ choices appropriate for importing the interchange files.

After importing the Porcupine Wash ARC/INFO interchange files, the pwash/ directory contains five map coverages, two dictionaries, four symbolsets, and three documentation files:

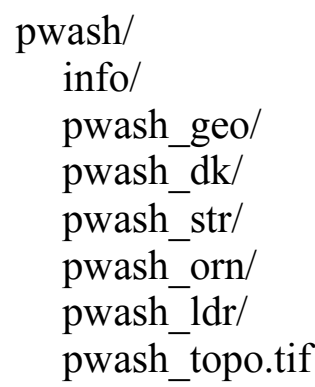

$\begin{array}{ll}\text { lines.rel } & \text { pwash_readme.txt } \\ \text { points.rel } & \text { pwas__met.txt } \\ \text { geoscamp2.lin } & \text { pwash_pamph.txt } \\ \text { geoscamp2.mrk } & \\ \text { scamp2.shd } & \\ \text { geology2.shd } & \end{array}$

The info/ directory contains INFO files integral to the database coverages.

ARC/INFO interchange files can be read by some other Geographic Information Systems, including ARCVIEW (ESRI) and MapInfo (via ArcLink). Please consult your GIS documentation to see if your system recognizes ARC interchange files and follow the procedure to import them. (NOTE: the graphical symbols contained in the two symbolsets (geoscamp2.lin; geoscamp2.mrk) cannot be read in ARCVIEW.) 


\section{DATABASE CONTENTS AND STRUCTURE}

This readme section contains tabular listings that summarize the structure and content of the database. Refer to the metadata for a complete technical description of the database structure and content; refer to the explanatory pamphlet for a discussion of the approach used in building the database within the context of its purpose and geologic database.

The database files comprise:

- ARC/INFO coverages

- INFO tables that contain line and point dictionaries

- Symbolsets

- Topographic base map: 500-dpi raster scan of USGS Porcupine Wash 7.5 minute quadrangle (provisional edition, 1986), registered and rectified to the coverage quadrangle in ARC/INFO and saved as a Georeferenced Tagged Image Format (GEOTIFF) file

\begin{tabular}{|c|c|c|c|}
\hline $\begin{array}{l}\text { Directory } \\
\text { or file name }\end{array}$ & $\begin{array}{l}\text { Directory } \\
\text { or file type }\end{array}$ & $\begin{array}{l}\text { Directory or } \\
\text { file contents }\end{array}$ & File size \\
\hline pwash_geo/ & ARC/INFO coverage & Geologic units and contacts & \\
\hline pwash_dk/ & ARC/INFO coverage & Dikes & \\
\hline pwash_str/ & ARC/INFO coverage & Geologic structure & \\
\hline pwash_orn/ & ARC/INFO coverage & Ornamentation & \\
\hline pwash_ldr/ & ARC/INFO coverage & Leaders & \\
\hline pwash_topo.tif & GEOTIFF & Raster-scanned topographic map & $13.1 \mathrm{MB}$ \\
\hline lines.rel & INFO table & Line dictionary & \\
\hline points.rel & INFO table & Point dictionary & \\
\hline geoscamp2.lin & Lineset & Lines & \\
\hline geoscamp2.mrk & Markerset & Points & \\
\hline scamp2.shd & Shadeset & Colors & \\
\hline geology2.shd & Shadeset & Patterns & \\
\hline
\end{tabular}




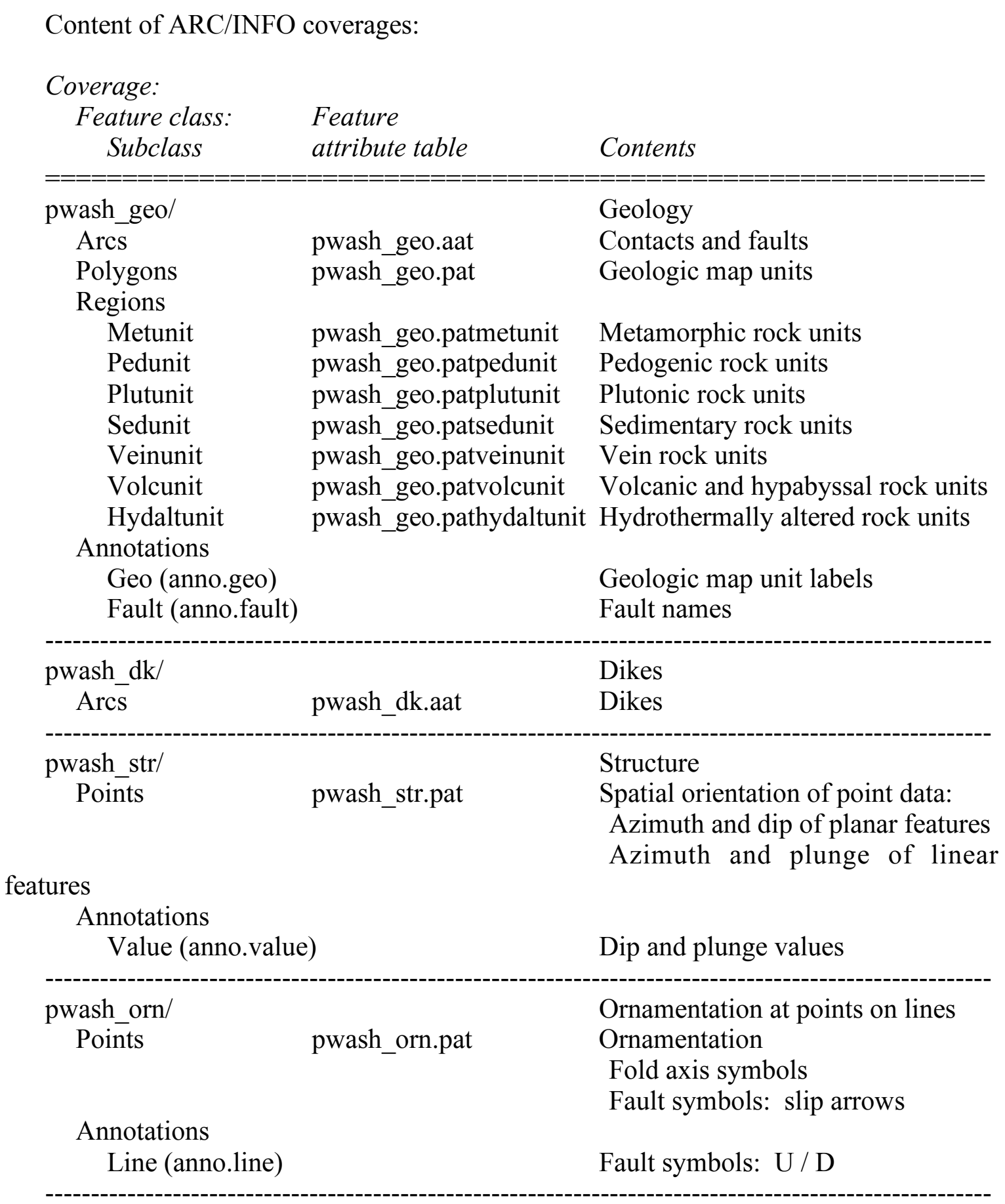

\begin{tabular}{|c|c|c|}
\hline $\begin{array}{l}\text { Coverage: } \\
\text { Feature class: } \\
\text { Subclass }\end{array}$ & $\begin{array}{l}\text { Feature } \\
\text { attribute table }\end{array}$ & Contents \\
\hline $\begin{array}{l}\text { pwash_ldr/ } \\
\text { Arcs }\end{array}$ & wash_ldr.aat & $\begin{array}{l}\text { Leaders for annotated unit labels } \\
\text { Leaders }\end{array}$ \\
\hline
\end{tabular}




\section{HOW TO OBTAIN A PAPER PLOT OF THE GEOLOGIC MAP}

1. Download and, using a gzip utility (see 'Extracting the database files' above), uncompress the file pwash_map.ps.gz. The 244-MB file pwash_map.ps is a PostScript plot-file of the geologic map and its explanation. The PostScript file will plot a 1:24.000scale, full-color geologic map of the Porcupine Wash quadrangle on its topographic base and accompanied by a map-margin explanation. The plot has a format similar to the U.S. Geological Survey's Miscellaneous Investigations (MF) map series, and is approximately 33 x 44 inches in size. It has been plotted successfully on Hewlett-Packard large-format plotters, models HP650C, HP755CM, and HP2500C using 36 x 48-in paper.

To add a topographic base to the geologic map, the monochromatic raster-scan file (pwash_topo.tif) and the geologic map coverages were converted to ARC/INFO grids. The grids were then merged to display the topographic and cultural information from the raster scan in gray, with geologic map unit colors filling the intervening areas of the topographic map. The combined map is a digital image in which geologic and topographic lines and points are displayed in their proper geospatial locations, but in which no information other than location is attached to the lines and points.

The marginal explanation includes a Correlation of Map and Database Units diagram, a Description of Map and Database Units, and a key to line and point symbols. The map margin explanation was created in Adobe Illustrator and imported into ARC/INFO to combine it with the geologic map.

The plot files have been prepared using line- and point-symbols and unit colors and patterns located in the following symbolsets:

$\begin{array}{ll}\text { geoscamp2.lin } & \text { Lines } \\ \text { geoscamp2.mrk } & \text { Points } \\ \text { scamp2.shd } & \text { Colors } \\ \text { geology2.shd } & \text { Patterns }\end{array}$

These sets are included in the pwash.tar.gz data package and are available at the Southern California Areal Mapping Project (SCAMP) website

http://geology.wr.usgs.gov/wgmt/scamp/attrib/attribute.html

In addition, the plot files contain specialized geologic-age fonts of the GeoAge font group, which is accessed through geofont.txt and is available from the USGS by anonymous ftp:

Server: onyx.wr.usgs.gov

Directory: /pub/wpg/supplies/geoage/.

2. Download and plot the 5.4-MB file pwash_map.pdf, which generates a paper map equal in quality to that of the much larger post-script plot file. Care must be taken to select a page size format that results in 1:24,000-scale map-plot. 


\section{HOW TO ACCESS PORTABLE DOCUMENT FORMAT (.PDF) FILES}

The .pdf files are accessed using Adobe Acrobat Reader software, available free of charge from the Adobe web site (http://www.adobe.com).

\section{HOW TO OBTAIN METADATA}

Metadata for the Porcupine Wash geologic map database are available as part of the National Spatial Data Infrastructure through the USGS Geologic Division Node of the National Geospatial Data Clearinghouse (http://nsdi.usgs.gov/). Within this site, OpenFile Reports are located at

http://geo-nsdi.er.usgs.gov/cgi-bin/publication?open-file

where they are listed by OFR number along with the title. Metadata at this node are viewable in five formats (ASCII as parseable text; HTML outline, HTML as answers to questions, XML, and DIF). Metadata for the Porcupine Wash database site at this node is located at

http://geo-nsdi.er.usgs.gov/metadata/open-file/00-31/metadata.faq.html

ASCII text and HTML outline versions of the metadata are also available at the Porcupine Wash website (http://geopubs.wr.usgs.gov/open-file/of01-30) and bundled with database files in the tarred and gzipped file. 


\section{LIST OF URLS CITED}

\section{U.S. Geological Survey websites}

Porcupine Wash 7.5 minute quadrangle

Open-File Report: http://geopubs.wr.usgs.gov/open-file/01-30

Metadata: http://geo-nsdi.er.usgs.gov/metadata/open-file/01-30/metadata.faq.html

Southern California Areal Mapping Project (SCAMP) website

GIS attributes: http://geology.wr.usgs.gov/wgmt/scamp/attrib/attribute.html

Databases: http://geology.wr.usgs.gov/wgmt/scamp/

Western Region Geologic Publication Server

Open-File Reports:

http://geopubs.wr.usgs.gov/open-file/of00- (followed by the OFR number)

All digital publications

http://geopubs.wr.usgs.gov/

U.S. Geological Survey website (http://geology.usgs.gov)

Open-File Reports

Digital maps: http://geology.usgs.gov/open-file/maps.html

Metadata: http://geo-nsdi.er.usgs.gov/cgi-bin/publication?open-file

Metadata (USGS Node of the National Geospatial Data Clearinghouse)

http://nsdi.usgs.gov/

National Geologic Map Database

http://ncgmp.usgs.gov/ngmdbproject/standards/

http://geology.usgs.gov/dm/ 


\section{Software websites}

GIS systems

Environmental Systems Research Institute (ESRI): http://www.esri.com

MapInfo: http://www.mapinfo.com

Compression and tar software

Gnu Software: http://www.gnu.org/order/ftp.html (UNIX tar and gzip)

(This web page links to mirror archive sites for Gnu tar and gzip utilities)

Gnu zip: http://www.gzip.org (UNIX gzip)

CNET Shareware: http://shareware.cnet.com/ (Macintosh and Windows)

(Search for 'tar' or 'gzip' for any Macintosh or Windows operating system.)

WinZip: http://www.winzip.com (Windows gzip)

USGS Public Domain Software web page:

http://edcwww.cr.usgs.gov/doc/edchome/ndcdb/public.html (UNIX, Macintosh)

(Provides links to Washington University at St. Louis Gnu archive for UNIX

tar and gzip; and to AOL mirror site for Macintosh tar and gzip)

Internet Literacy's Common Internet File Formats:

http://www.matisse.net/files/formats.html (Macintosh and Windows tar and gzip)

(Note: this website has not been maintained since December 1995)

\section{Portable document reader}

Adobe web site: http://www.adobe.com 